\title{
Intimate relationship and persons with learning disability
}

Claire Azzopardi Lane

This is an author produced version of a paper published in Tizard Learning Disability. This paper has been peer-reviewed but does not include final publisher proof-corrections or journal pagination.

Citation for the publisher paper

Claire Azzopardi-Lane, (2017) "Intimate relationships and persons with learning disability", Tizard Learning Disability Review, Vol. 22 Issue: 1, pp.24-27, https://doi.org/10.1108/TLDR-10-2016-0037 


\title{
Intimate relationships and persons with learning disability
}

\author{
Claire Azzopardi-Lane
}

\section{Abstract}

Purpose - The purpose of this paper is to provide a commentary on the paper "Supporting people with learning disabilities to make and maintain intimate relationships".

Design/methodology/approach - Comparison of the sexual rights of persons with disability, as outlined in the 2006 Convention on the Rights of Persons with Disability, with research on actual policy and practice.

Findings - The sexual expression of persons with learning disability remains suppressed by those in positions of power, such as parents and service providers.

Originality/value - While there remains a long way to go, the commentary points towards examples of empowering policies and good practice that may shift the discourse towards sexual rights and emancipation of persons with learning disability.

Keywords - Learning disabilities, Intellectual disability, Sexuality, Empowerment, Intimate relationships, Sexual rights

Paper type - Viewpoint

Research exploring non-disabled people's attitudes towards the sexuality of persons with learning disability confirms the persistence of a "deep sense of unease" towards the idea of persons with learning disability being sexually intimate, getting married and (even more so) having children (Hamilton, 2010, p. 4). This is notwithstanding Article 23 of the Convention on the Rights of Persons with Disability (2006), that underlines the rights of persons with disability to explore and express their sexuality. 
It is clear, from this type of research, that professionals and service providers working with people with learning disability are likely to have difficulty addressing issues of sexuality, whilst establishing policy with regards to sexual expression is considered challenging (Conahan et al., 1993; Azzopardi Lane, 2011; Azzopardi-Lane and Callus, 2014). Policies are meant to formally guide service providers towards managing the complex issues of sexuality (Cambridge and Mellan, 2000). Yet disability services are known for lacking policies facilitating sexual experiences and staff training on sexuality (Noonan and Taylor Gomez, 2010). It is also claimed that often service providers and staff have not been given clear instructions about their roles and responsibilities in regard to the sexual lives of people with learning disability (Conahan et al., 1993). This lack of direction in developing guidelines may be due to the absence of consensus on these issues amongst professionals facing the challenging task of establishing policy regarding sexual expression. Cambridge (1997) maintains that without policy development and consistency of service responses, the lives of people with learning disability will remain undervalued and their opportunities for sexual expression restricted. Conahan et al. (1993, p. 318) conclude that; "the question is not whether the person understands sexuality or is sexual, but rather, how the provider ensures his right to pursue his interest safely and with regard to the rights of other in treatment".

Establishing whether a person with learning disability has the capacity to consent to a sexual relationship has also not been an easily agreed upon matter (Kennedy and Niederbuhl, 2001). There is general agreement that capacity to consent to sexual relationships is strongly associated with sexual knowledge (Niederbuhl and Morris, 1993; McCarthy, 1999; McCabe, 1999).Suggested criteria of knowledge required to engage in sexual relationships are: understanding what sexual relationships are; understanding the risks, benefits and alternatives of such relationships; and recognizing the fact that those involved have free choice on whether to engage in them (Murphy and O'Callaghan, 2004).

Social attitudes that lie at the very roots of society strongly influence the lives of people with disability. Social attitudes not only affect the lives of the persons directly involved, but also the beliefs of their parents, guardians and service providers. Disabling attitudes and institutional structures have robbed people with a disability of opportunities, experiences and equality. Consequently, attitudes of service providers and families often present obstacles to 
the development of relationships and to the sexual lives of people with learning disability (Johnson et al., 2002).

A number of studies by researchers such as Morris (1989), Owens and Child (1999) (cited in Selina, 2002), Shakespeare (2000), Selina (2002) and Azzopardi Lane (2011) have documented the genuine beliefs of many non-disabled people that disabled people are incapable of enjoying sexual expression and pursuing sexual pleasure responsibly. Hamilton (2010, p. 3) also asserted that beliefs that equate people with learning disability with "an inferior, abnormal, unequal and subordinate social position" jeopardize their sexual equality.

Comparable cultural attitudes around the subject of sexuality and people with disability were found in research carried out in Ireland and Malta (Selina, 2002; Azzopardi Lane, 2011). In the research conducted in Malta with people with learning disability, their parents and service providers (Azzopardi Lane, 2011), participants emphasized the conflict between religion and the sexuality of persons with disability amongst other culturally-related issues. As Selina (2002, p. 2) affirms:

Traditionally there has been a taboo around discussing sex and related matters in public. Sex was for marriage and procreation, and disabled people were not expected or encouraged to experience either.

Pownall et al. (2011) further underlined how social exclusion not only limited access to formal sources of sexual information but also to opportunities of establishing relationships. Such problems persist even after moving out of the parental home (Wheeler, 2004), when restrictions of autonomy and privacy are still encountered. Wheeler's (2004) findings illustrate how people with learning disability continue to lead restricted lives whether in institutional settings or other living arrangements such as houses in the community (McCarthy, 1999).

Parents of people with learning disability as well as service providers, in research by Azzopardi Lane (2011), claimed that they would want to have a say in the relationships of persons with disability. This "say" ranged from just keeping an eye on the couple and facilitating in times of difficulty - to intervening in their more intimate relations and, if required, restricting sexual 
expression. It transpired that parents preferred platonic relationships rather than intimate and sexual relationships (Azzopardi Lane, 2011). Doubts about people with learning disability being able to make sensible choices independently, in relation to contraception and sexual relationships, were also reported inJahoda and Pownall's (2014) research. The majority of parents in Azzopardi Lane (2011) were concerned about pregnancy and said that they would want their sons and daughters not to have their own children. Whilst family support in raising children in a Maltese context is considered thecultural norm (Cutajar, 2003), parents of persons with disability claimed that they did not wish to have the responsibility to raise their grandchildren (Azzopardi Lane, 2011). Davies and Jenkins(1997) and Block (2002) also found that a number of parents in their study preferred to discourage their children from marriage and parenting, or simply prevented them from having sexual relationships. Gender bias also emerged as parents presented themselves as more protective and less willing to let their daughters get involved in relationships than their sons (Dilorio et al., 2003; Wheeler, 2004; Pownall et al., 2011; Azzopardi Lane, 2011).

Azzopardi Lane (2011) reported on the implications faced by persons with learning disability when parents did not approve of their relationships. If parents of the couple with disability, who are in love, are opposed to their feelings, the disabled couple do not have much chance of find in alternative support (Azzopardi Lane, 2011). In the same study participants with learning disability said they believed that their parents would not like it if they had a sexual relationship and seriously doubted whether their residential setting would allow them to pursue an intimate relationship (Azzopardi Lane, 2011).

Service providers in Azzopardi Lane (2011) agreed with persons with learning disability having platonic but not intimate relationships. Day centres for persons with learning disability have been reported (Davies and Jenkins, 1997) to restrict the opportunities for people with learning disability to be in a relationship, fostering a "culture of caution and prohibition" (Johnson et al., 2002). 
Despite these reports, research recommends that services need to achieve a balance between ensuring the safety of vulnerable people and the possibility of happy, fulfilling relationships (Carson and Blyth, 2009; Noonan and Taylor Gomez, 2010). Independent living services and sexuality can thus be seen as interrelated (National Disability Policy, Malta, 2014). Apart from providing the possibility of living independently of the family, such services can also aim to give persons with learning disability more autonomy and opportunities, including that of engaging in intimate relationships (National Disability Strategy, Malta, 2016).

Self-advocacy skills oriented around sexuality have been seen as another way of establishing sexual rights (Azzopardi-Lane and Callus, 2014). Callus (2011) argued that self-advocacy not only empowers people with learning disability to speak for themselves, but also helps to dispel myths about their inability to do things. Self-advocacy re-affirms that persons with learning disability can in fact speak up, take their own decisions and take responsibility for themselves (Callus, 2011). Thus, combining this with the subject of sexuality and intimate relationships can be a powerful way of dispelling myths and pursuing the sexual emancipation of persons with learning disability (Azzopardi-Lane and Callus, 2014).

\section{References}

Azzopardi Lane, C. (2011), "People with learning disability and sexuality; realities and potentials", unpublished PhD thesis, University of Kent, Kent.

Azzopardi-Lane, C. and Callus, A.M. (2014), "Constructing sexual identities: people with intellectual disability talking about sexuality", British Journal of Learning Disabilities, Vol. 43 No. 1, pp. 32-7.

Block, P. (2002), "Introduction to the special issue: parents with disabilities", Sexuality and Disability, Vol. 20 No. 1, pp. 3-5.

Callus, A.M. (2011), "A qualitative study of the self-advocacy movement for people with the label 'intellectual disability' in Malta", unpublished PhD thesis, University of Leeds, Leeds. 
Cambridge, P. (1997), HIV, Sex and Learning Disability: A Staff Training and Sex Education Resource for Working on HIV and with Men with Learning Disabilities Who Have Sex with Men, Pavilion, Brighton.

Cambridge, P. and Mellan, B. (2000), "Reconstructing the sexuality of men with learning disabilities: empirical evidence and theoretical interpretations of need", Disability and Society, Vol. 15 No. 2, pp. 293-311.

Carson, I. and Blyth, C. (2009), "Lonely hearts need a helping hand", Learning Disability Today, pp. 18-21.

Conahan, F., Robinson, T. and Miller, B. (1993), “A case study relating to the sexual expression of a man with developmental disability", Sexuality and Disability, Vol. 11 No. 4, pp. 309-18.

Cutajar, J. (2003), "Teenage mothers - the right to work and study", paper presented at the Young Unmarried Mothers Seminar, Gozo.

Davies, D. and Jenkins, R. (1997), "She has different fits to me: how people with learning disabilities see themselves", Disability and Society, Vol. 12 No. 1, pp. 95-109.

Dilorio, C., Pluhar, E. and Belcher, L. (2003), "Parent-child communication about sexuality: a review of the literature from 1980-2002", Journal of HIV/AIDS Prevention and Education for Adolescents and Children, Vol. 5 Nos 3-4, pp. 7-32.

Hamilton, C. (2010), "Not a remotely suitable topic: analyzing community responses to the issue of gynaecological surgery", 3rd IASSID-Europe Conference: Integrating Biomedical and PsychoSocialEducational Perspectives, Rome.

Jahoda, A. and Pownall, J. (2014), "Sexual understanding, sources of information and social networks: the reports of young people with intellectual disabilities and their non-disabled peers", Journal of Intellectual Disabilities, Vol. 58 No. 5, pp. 430-41.

Johnson, K., Frawley, P., Hillier, L. and Harrison, L. (2002), "Living safer sexual lives: research and action", Tizard Learning Disability Review, Vol. 7 No. 3, pp. 4-8.

Kennedy, C. and Niederbuhl, J. (2001), "Establishing criteria for sexual capacity consent", American Journal on Mental Retardation, Vol. 106 No. 2, pp. 503-10. 
McCabe, M. (1999), "Sexual knowledge, experiences and feelings among people with disability", Sexuality and Disability, Vol. 17 No. 2, pp. 157-70.

McCarthy, M. (1999), Sexuality and Women with Learning Disabilities, Jessica Kingsley Publishers, London.

Morris, J. (1989), Able Lives, Women's Press, London.

Murphy, G.H. and O'Callaghan, A. (2004), "Capacity of adults with intellectual disabilities to consent to sexual relationships", Psychological Medicine, Vol. 34 No. 7, pp. 1-11.

National Disability Policy, Malta (2014), "Sexuality and parenthood", available at: https://activeageing.gov.mt/en/Pages/National-Policy-on-the-Rights-of-Persons-with-

Disability.aspx (accessed October 2016).

National Disability Strategy, Malta (2016), "Sexuality and parenthood", available at: https://activeageing.gov.mt/en/Pages/Malta-National-Disability-Strategy.aspx （accessed October 2010).

Niederbuhl, J. and Morris, C. (1993), "Sexual knowledge and the capability of persons with dual diagnoses to consent to sexual contact", Sexuality and Disability, Vol. 11 No. 4, pp. 295307.

Noonan, A. and Taylor Gomez, M. (2010), “Who's missing? Awareness of lesbian, gay, bisexual and transgendered people with intellectual disability", Sexuality and Disability, Vol. 29 No. 2, pp. $175-80$.

Pownall, J., Jahoda, A., Hastings, R. and Kerr, L. (2011), "Sexual understanding and development of young people with intellectual disabilities: mothers' perspectives of withinfamily context", American Journal onIntellectual and Developmental Disabilities, Vol. 116 No. 3, pp. 205-19.

Selina, B. (2002), "Facilitated sexual expression in the Independent Living Movement in Ireland", available at: www.independentliving.org/docs6/bonnie200208.html (accessed October 2016).

Shakespeare, T. (2000), "Disabled sexuality: toward rights and recognition", Sexuality and Disability, vol. 18 No. 3, pp. 159-66. 
Wheeler, P. (2004), "I count myself as normal: an exploratory study of men with learning disabilities telling their stories about sexuality and sexual identity", unpublished PhD thesis, University of Kent, Kent.

\section{Corresponding author}

Claire Azzopardi-Lane can be contacted at: claire.azzopardi-lane@um.edu.mt 